\title{
Panoramik Radyografide Kök Apikalinde Karanlık Alan Görüntüsü Veren Alt Üçüncü Molar Dişlerin İnferior Alveolar Sinir Komşuluğunun ve Lingual Kortekste Oluşturduğu Perforasyon Sıklığının Değerlendirilmesi
}

\section{Evaluation of Lingual Cortex and Inferior Alveolar Canal Perforation Caused by Mandibular Third Molar Teeth Which Shows Darkening at The Root Apical in Panoramic Radiography}

\author{
Şebnem AKKÜLAH ${ }^{1}$ (D) \\ sebnemakkulah12@gmail.com
}

\author{
Alparslan ESEN ${ }^{* 1}$ (iD \\ aesen@erbakan.edu.tr
}

\begin{abstract}
ÖZ
Amaç: Bu geriye dönük çalışmanın amacı, panoramik radyografide kök apikalinde inferior alveolar kanal üzerinde karanlık alan oluşmasına sebep olan alt üçüncü molar dişlerin konik ışınlı bilgisayarlı tomografi (KIBT) görüntülerinde alveolar sinir ile ilișkisini ve lingual korteks perforasyon sıklığını değerlendirmektir.

Gereç ve Yöntemler: Çalışmaya panoramik radyografilerinde alt üçüncü molar dişlerin inferior alveolar kanal üzerinde karanlık alan oluşturan ve KIBT görüntüleri mevcut olan toplam 107 hasta dâhil edildi. Kök apikalinde karanlık alan oluşturduğu belirlenen toplam 122 gömülü diş KIBT’ de üç farklı düzlemde (aksiyal, sagital, koronal) inferior alveolar kanal korteksi (İAKK) ve lingual korteks (LK) perforasyon sıklığı açısından değerlendirildi.

Bulgular: İncelenen 122 dişin 62'sinde İAKK devamlılığında bozulma görüldü. Bu dişlerin 2 tanesinde ise hem İAKK hem de LK devamlılığında bozulma izlendi. Kalan 60 diște ise İAKK korunmuştu. Ancak bu dişlerin 20 tanesinin lingual tarafta yerleșim gösterdiği ve bu dișlere komșu LK devamlılığında bozulma meydana geldiği görüldü.

Sonuç: Panoramik radyografide gömülü yirmi yaş dişlerinin inferior alveolar kanal üzerinde karanlık alan oluşturduğu durumlarda, bu dişlerin yarısına yakınının kanalla ilişkili olabileceği akılda tutulmalıdır. Aynı zamanda bu tür dişlerin lingual kortekste perforasyon ihtimalinin de göz önünde tutulması, cerrahi işlem sırasında lingual sinir ve yumuşak doku yaralanmasını engellemek adına faydalı olabilir.
\end{abstract}

Anahtar Kelimeler: Gömülü diș, Oral cerrahi, Komplikasyonlar

Geliș: 22.02 .2021

Kabul: 30.03.2021

Yayın: 30.04.2021

\begin{abstract}
Aim: The aim of this retrospective study is to evaluate the relationship between the alveolar nerve and the frequency of lingual cortex perforation in the conical beam computed tomography (CBCT) images of the mandibular third molar teeth, which causes darkening of the roots on the inferior alveolar canal on panoramic radiography.

Materials and Methods: A total of 107 patients who had a dark area on the inferior alveolar canal of lower third molar teeth in their panoramic radiographs and had CBCT images were included in the study. 122 impacted third molar teeth determined to create a dark area in the root apical were evaluated in terms of the frequency of perforation in the inferior alveolar canal cortex (IACC) and lingual cortex (LC) in three different planes (axial, sagittal, coronal).

Results: Interruption of the continuity of IACC was observed in 62 of 122 teeth. In 2 of these teeth, both IACC and LC continuity interrupted. In the remaining 60 teeth, IACC continuity was preserved. However, 20 of these teeth were located on the lingual part and these teeth showed LC perforation.

Conclusion: It should be kept in mind that half of these teeth may be related to the canal in cases that impacted mandibular third molars create a dark area on the inferior alveolar canal in panoramic radiography. At the same time, considering the possibility of perforation of such teeth in the lingual cortex, it may be useful to prevent lingual nerve and soft tissue injury during the surgical procedure.
\end{abstract}

Keywords: Impacted tooth, Oral surgery, Complications

Received: 22.02.2021 Accepted: 30.03.2021 Published: 30.04 .2021

Atıf / Citation: Akkülah Ş, Esen A. Panoramik radyografide kök apikalinde karanlık alan görüntüsü veren alt üçüncü molar dişlerin inferior alveolar sinir komşuluğunun ve lingual kortekste oluşturduğu perforasyon sıklığının değerlendirilmesi. NEU Dent J. 2021;1:14-8.

* Sorumlu Yazar / Corresponding Author

1. Necmettin Erbakan Üniversitesi Diș Hekimliği Fakültesi Ağız, Diș ve Çene Cerrahisi AD Konya,

Türkiye

"This article is licensed under a 


\section{GíRiş}

Alt gömülü üçüncü molar (GM3) dişlerin çekimi oral cerrahide en sık uygulanan ișlemlerden biridir. Bu nedenle çekim öncesi risk faktörlerini değerlendirmek önemlidir. Ağrı, șișlik, hematom ve trismus gibi sık gelişebilecek postoperatif komplikasyonların yanı sıra inferior alveolar sinirde parestezi gelişmesi de önemli komplikasyonlardan biridir. Bu komplikasyon hekimin deneyimine, köklerin uzunluğuna, dișin pozisyonuna ve kök apikallerinin inferior alveolar kanalla mesafesine bağlıdır. İnferior alveolar sinirin geçici parestezisi literatürde $\% 0.5-5$ olarak bildirilmiștir. ${ }^{1,2}$ İnferior alveolar sinirin kalıcı parestezisinin sıklığ ise $\% 1$ olarak bildirilmiştir. Lingual korteks (LK) 'in kırılması ve kök parçalarının yumuşak dokulara deplase olması nadir ancak ciddi komplikasyonlardandır., ${ }^{3,4} \mathrm{Bu}$ komplikasyonlar hematoma, lingual sinir hasarına ve ağız tabanında bir enfeksiyon gelişmesine sebep olabilir.,5 Bunun yanı sıra kısıtlı çalışma alanı ve ağız açıklığına bağlı olarak kök parçalarını çıkarmak zorlaşır. ${ }^{7}$

$\mathrm{Bu}$ ve benzeri komplikasyonlardan kaçınmak için ișlem öncesi değerlendirmede en sık kullanılan görüntüleme yöntemi düşük radyasyon dozuna sahip olması ve ucuz olması sebebiyle panoramik radyografidir. ${ }^{8}$ Panoramik radyografide GM3 dişlerin inferior alveolar kanalla ilișki riskini arttıran yedi ölçüt belirlenmiştir. ${ }^{9}$ Ancak panoramik radyografi iki boyutta değerlendirme sağlar ve ilişki konusunda kesin bir bilgi vermez. Dişin kanalla olan ilişkisi daha ileri bir görüntüleme yöntemi olan bilgisayarlı tomografi ya da konik ışınlı bilgisayarlı tomografi (KIBT) ile kesin olarak belirlenir. Ancak bu görüntüleme yöntemi yüksek maliyetli olması, panoramik radyografiye göre yüksek doz radyasyona sebep olması ve her merkezde bulunmaması gibi dezavantajları sebebiyle rutin olarak GM3' lerin inferior alveolar kanalla ilişkisinin değerlendirilmesinde kullanılamamaktadir. $^{10}$

Bu çalıșmanın amacı panoramik radyografide kök- lerde karanlık alan olușturan GM3 dișlerinin KIBT görüntülerinde kanalla ilișkisi ve LK perforasyon sıklığını değerlendirmektir.

\section{GEREÇ VE YÖNTEMLER}

Bu çalışma için Necmettin Erbakan Üniversitesi, Diş Hekimliği Fakültesi Etik Kurulu'ndan 2020-06 numaralı etik kurul onayı alınmıștır. Çalıșmaya inferior alveolar kanal üzerinde karanlık alan olușturan ve KIBT görüntüleri mevcut olan 122 adet GM3 diș dâhil edilmiştir. KIBT ve panoramik radyografiler üreticinin önerilen talimatlarına göre (Morita Veraviewepocs 3D R100-P, J Morita MFG Corp., Kyoto , Japan) $70 \mathrm{kVp}, 10 \mathrm{~mA}$ ve $10 \mathrm{~s}^{\prime}$ de çekilmiștir. KIBT görüntüleri hasta oturur pozisyonda iken Morita 3D Accuitomo 170 sistem (J Morita MFG Corp., Kyoto , Japan) $90 \mathrm{kVp}$ ve $5 \mathrm{~mA}$ 'de, rotasyon süresi 17.5 saniye, 0.25 mm voksel aralığında, görüntüleme alanı $100 \mathrm{~mm}$ olacak șekilde üretici firmanın talimatlarına uyarak çekilmiştir. KIBT görüntüleri 21.5 inçlik düz ekranda 2560x1600 çözünürlüğünde karanlık bir odada 3 farklı düzlemde (aksiyel, koronal, sagital) değerlendirilmiștir. Panoramik radyografide kök apikalinde karanlık alan oluşturan dişlerin KIBT görüntüleri ile inferior alveolar kanalla ilişkisi ve lingual korteks perforasyon sıklığı değerlendirilmiștir.

\section{BULGULAR}

Panoramik röntgende inferior alveolar kanal sinırında köklerde karanlık alan görüntüsü veren 107 hastaya ait, (36 erkek, 71 kadın) 122 adet GM3 diş incelenmiștir. Ortalama yaș 26,56' dır. KIBT değerlendirmesinde toplam 62 dișin köklerinin İAKK devamlılığını engellediği izlendi (Resim-1a,1b). İAKK kaybı meydana getiren bu dișlerin yalnızca 2 tanesinin LK' da perforasyon oluşturduğu gözlendi. Geriye kalan 60 diște ise İAKK' da devamlılığın bozulmadığı görüldü. İAKK devamlılığını bozmayan bu dișlerin ise 20 tanesinin lingualde konumlandığ 1 ve $\mathrm{LK}^{\prime}$ yl perfore ettiği belirlendi (Resim-2a,2b).
Resim 1a: Sol alt premolar-molar bölgesinde diş köklerinden bağımsız yerleşim gösteren yuvarlak șekilli IO lezyonu

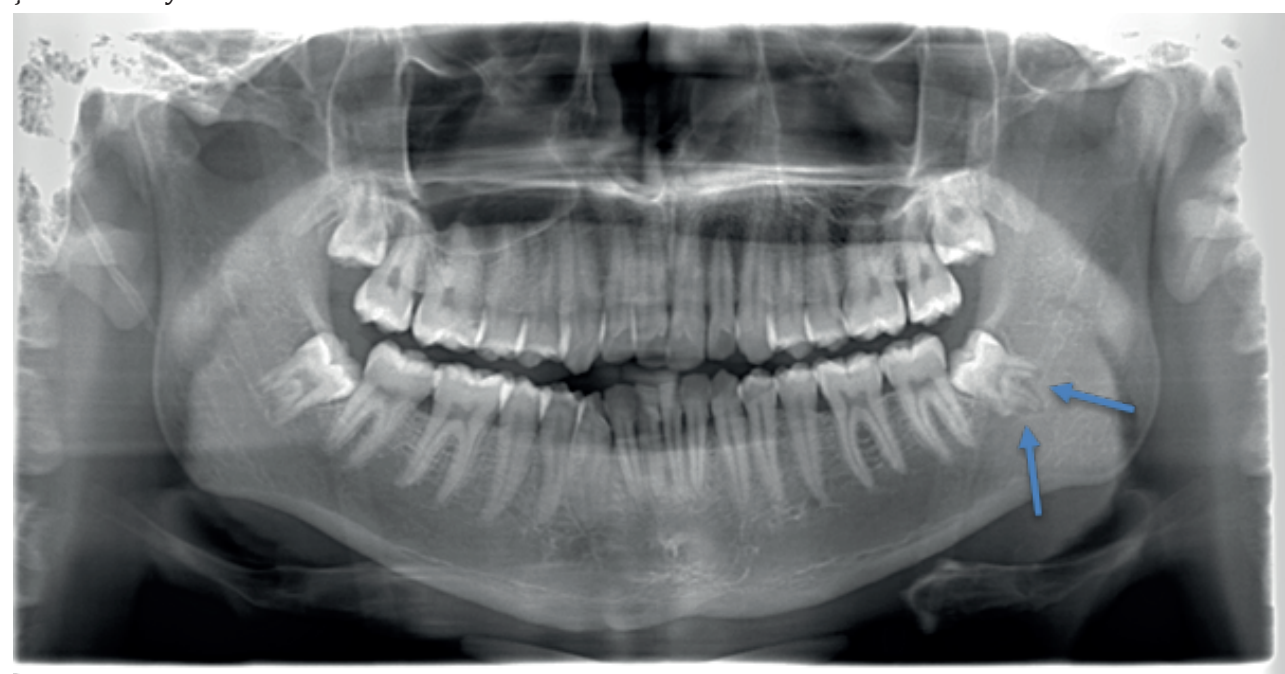

Resim 1b: Bağımsız yerleșim gösteren yuvarlak șekilli IO lezyonu

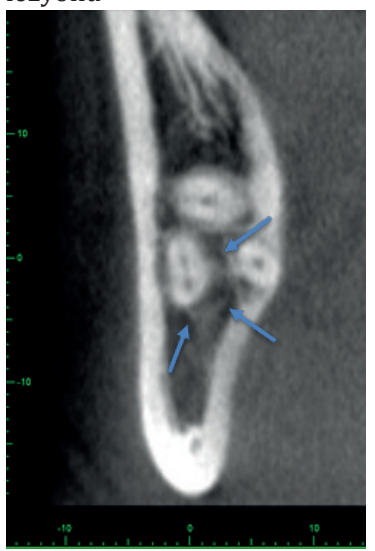

KIBT görüntüsünde aynı dișin kökünün alveolar sinirle olan ilișkisi ve mandibular kanal olar sinirle olan ilişkisi ve mandibular kanal
devamlılığının bozulduğu görülmektedir. Oklarla kanalın çeperi gösterilmiștir. Kanal devamlılığı kökün bulunduğu tarafta kesinti ye uğramıştır. 
Resim 2a: Sağ mandibular gömülü üçüncü molar dișin kök apikali çevresinde karanlık alan izlenmektedir.

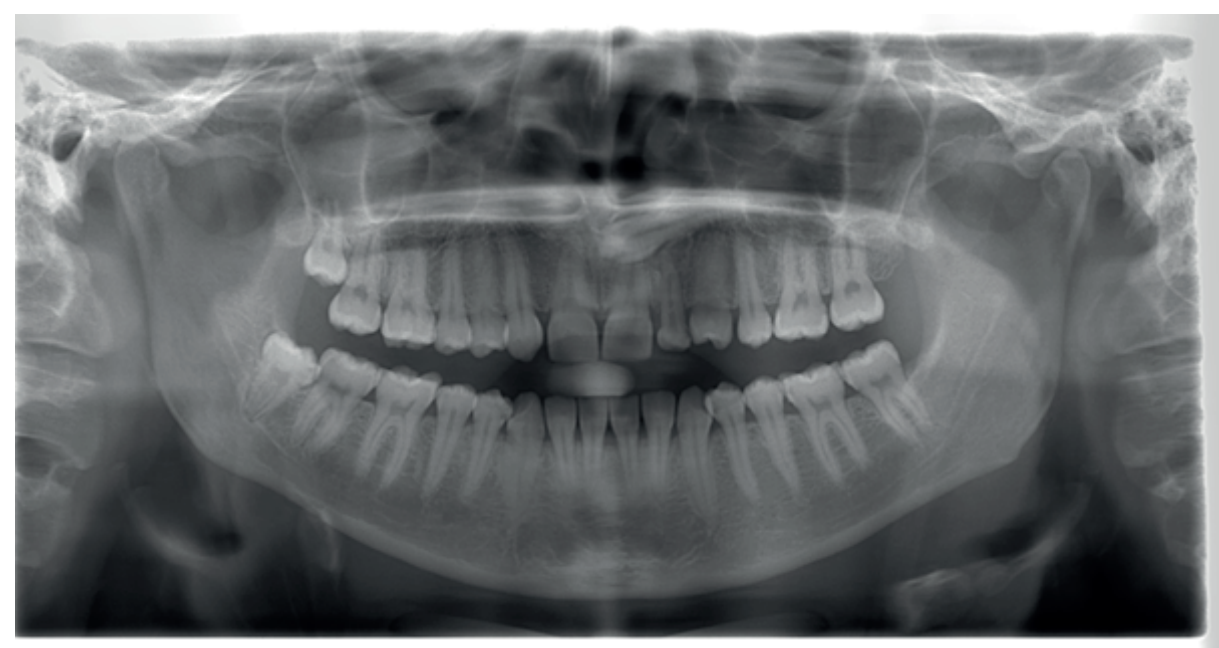

Resim 2b: Aynı dişin KIBT görüntüsünde lingual korteks perforasyonu net olarak izlenmektedir.

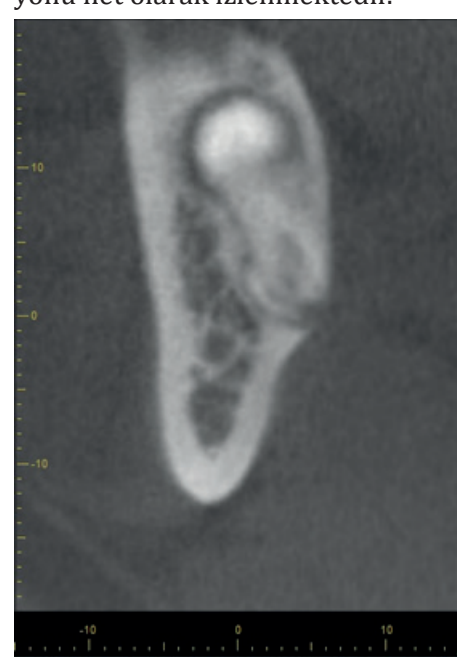

\section{TARTIŞMA}

GM3 dișlerinin çekimi oral ve maksillofasiyal cerrahi kliniklerinde en slk uygulanan ișlemlerden biridir. Dișlerin inferior alveolar kanalla ilișkisini belirlemek için en sık başvurulan görüntüleme yöntemi panoramik radyografidir. ${ }^{11}$ Daha önce bazı yazarlar tarafından panoramik radyografide dișin sinirle ilișki riskini arttıran 7 kıstas belirlenmiștir. ${ }^{9}$ Bu çalıșmada bu 7 ölçütten 'köklerde karanlık alan oluşturma' kriteri seçilerek panoramik radyografi görüntüleri KIBT görüntüleriyle kıyaslanmıştır.

Trigeminal sinir hasarı, hastaların yașam kalitesinin düşmesine, psikolojik ve sosyal problemlere sebep olur. ${ }^{12}$ Leung ve ark. ${ }^{13}$ trigeminal sinir hasarının yaşam kalitesi üzerine etkisini incelediği bir çalışmada 'fonksiyonel kısıtlanma, fiziksel ağrı, psikolojik problemler, psikolojik bozukluk, sosyal bozukluk ve engel' alt gruplarını kontrol ve çalışma grubunda kıyaslamış, gruplar arasında anlamlı bir fark bulmuştur.

Köklerde karanlık alan olușmasının LK' da incelmeye bağlı olabileceği ilk defa Mahasantipiya ve ark. ${ }^{14}$ tarafından bildirilmiştir. Tantapornkul ve ark..$^{15}$ ise karanlık alan oluşturan dișlerin \% 80' inin LK' yl incelttiğini bildirmiştir. GM3 dişlerinin lingualindeki kortikal kemik, lingual siniri korumaktadır. LK' nın incelmesi ya da bazı durumlarda perforasyonu bu bariyeri ortadan kaldırır ve diş ile sinir arasındaki mesafeyi azaltır. ${ }^{16} \mathrm{Bu}$ șekilde LK' nın inceldiği durumlarda lingual sinir hasarı, dișin ya da kemik parçasının sublinguale veya ağız tabanına dislokasyonu meydana gelebilir. Ayrica bu durum, hastaya olası riskler konusunda hem işlem öncesinde hem de sonrasında detaylı bilgi vermek gerektirir. Lingual kortikal kemiğin kırılması, alt üçüncü moların ya da kök parçalarının sublingual boşluğa ya da ağız tabanına deplase olması nadir ancak ciddi komplikasyonlar arasında bildirilmiştir. ${ }^{15}$ Stacy ve ark. ${ }^{17}$ GM3 çekimine bağlı LK perforasyonunun doğrudan submandibular loca ile bağlantı oluşturduğu için ciddi bir komplikasyon olduğunu bildirmiștir. Bir bașka çalışmada ise köklerde karanlık alan oluşması, KIBT' te LK' nın incelme göstermesi ile ilişkilendirilmiştir. Karanlık alan oluşturan bu dişlerin \%44.2' sinin LK' yı incelttiği bildirilmiştir. ${ }^{18}$

LK morfolojisi posterior mandibulada çekim sonrasi komplikasyonlar ve prognoz konusunda anahtar rolü oynar. ${ }^{19}$ Çeşitli çalışmalarda LK' nın morfolojisinin lingual kemik perforasyonu ile ilișkisi bildirilmiştir. ${ }^{16,20-22} \mathrm{Bu}$ çalıșmaların sonuçları da yirmi yaş dişlerinin köklerinin LK' ya çok yakın konumlandığı durumlarda cerrahi açıdan diş çekimi sırasında lingual kemikte kırılma riskinin yüksek olduğu sonucunu desteklemektedir. Bunun yanı sıra işlem sırasında kırılmış diş köklerinin veya debris artıklarının lingual loja migre olması da yüksek ihtimal dâhilindedir. Dikkatli bir cerrahi ișlemin uygulanmadığ durumlarda mandibula fraktürlerinin meydana gelmesi veya dişin tamamının lateral faringeal loja itilmesi de karşılaşılabilecek ciddi komplikasyonlar arasındadir. $^{23,24}$

Panoramik radyografide kök apikalinde karanlık görüntü veren ve LK perforasyonu ihtimali yüksek olan molar dişlerin endodontik tedavisinde de dikkatli olunması tavsiye edilmektedir. ${ }^{21} \mathrm{Bu}$ tedavide uygulanan irrigasyon solüsyonları, çeşitli medikal ajanlar veya kırılmış bir kanal eğesi parçası lingual loja itilebilir. Cerrahi veya endodontik tedavi sırasında bu bölgede oluşabilecek bir diğer istenmeyen durumun ise iatrojenik subkutanöz amfizem olduğu unutulmamalıdır.

Bilindiği gibi alt yirmi yaş dişlerinden kaynaklı en sık karşılaşılan enfeksiyon perikoronitistir. LK perforasyonu yapmış gömülü dişlerde, çevre yumuşak dokularda olușan böyle bir enfeksiyonun komșu yüz boşluklarına (lojlara) yayılması sonucu submandibular veya lateral faringeal gibi büyük loj apseleri meydana gelebilmektedir ${ }^{25}$. Dolayısiyla bu dişlerin cerrahi işleminden sonra oluşabilecek postoperatif bir enfeksiyonun, LK' nın ortadan kalkması sonucu daha alt bölgelere yayılmasının kolay olacağı akılda tutulmalıdır. 


\section{SONUÇ}

Alt yirmi yaş dişlerinin preoperatif dönemde radyografik olarak değerlendirilmesi önemlidir. Panoramik radyografilerde yirmi yaș dișlerinin kök apikallerinin çevresinde karanlık bir alan görüldüğü durumlarda, diş kökünün inferior alveolar kanal içinde yerleşmiş olabileceği veya kemiğin lingual korteksinde perforasyon riskinin yüksek olduğu hekim tarafından ön görülmelidir. Kesin bir kanıya varmak için bu hastalardan KIBT alınabilir. Bu durumda olan hastalar işlem öncesinde oluşabilecek parestezi ve diğer komplikasyonlar hakkında mutlaka bilgilendirilmelidir. Bunun yanı sıra alveolar kanal içinde yerleşmiş dişlerde hastalara koronektomi gibi alternatif tedavi yöntemleri de sunulabilir.

\section{KAYNAKLAR}

1. Szalma J, Lempel E, Jeges S, Szabó G, Olasz L. The prognostic value of panoramic radiography of inferior alveolar nerve damage after mandibular third molar removal: retrospective study of 400 cases. Oral Surg Oral Med Oral Pathol Oral Radiol Endod. 2010;109:294-302.

2. Blaeser BF, August MA, Donoff RB, Kaban LB, Dodson TB. Panoramic radiographic risk factors for inferior alveolar nerve injury after third molar extraction. J Oral Maxillofac Surg. 2003;61:417-21.

3. Atilgan S, Kaya G, Kose I, Koparal M, Gunes N, Atalay Y, Yaman F. Displaced lower third molar tooth into the submandibular space: Two case reports. Journal of Natural Science, Biology and Medicine. 2014;5:48284.

4. Zhao S, Huang Z, Geng T, Huang L. Intraoral management of iatrogenically displaced lower third molar roots in the sublingual space: a report of 2 cases. Int J Clin Exp Med. 2015;8(10):19591-19595.

5. Figueiredo R, Valmaseda-Castellón E, Laskin DM, Berini-Aytés L, Gay-Escoda C. Treatment of Delayed-Onset Infections After Impacted Lower Third Molar Extraction. Journal of Oral and Maxillofacial Surgery. 2008;66:943-47.

6. Jerjes W, Upile T, Shah P, Nhembe F, Gudka D, Kafas P, McCarthy E, Abbas S, Patel S, Hamdoon Z, Abiola J, Vourvachis M, Kalkani M, Al-Khawalde M, Leeson R, Banu B, Rob J, El-Maaytah M, Hopper C. Risk factors associated with injury to the inferior alveolar and lingual nerves following third molar surgery-revisited. Oral Surgery, Oral Medicine, Oral Pathology, Oral Radiology, and Endodontology. 2010;109:335-45.

7. Charan Babu HS, Reddy PB, Pattathan RK, Desai R, Shubha AB. Factors influencing lingual nerve paraesthesia following third molar surgery: a prospective clinical study. J Maxillofac Oral Surg. 2013;12:168-72.

8. Bordonaba-Leiva S, Gómez-Durán EL, Balibrea JM, Benet-Travé J, Martin-Fumadó C, Bescos Atin C, Mareque-Bueno J, Arimany-Manso J. Twenty four years of oral and maxillofacial surgery malpractice claims in Spain: patient safety lessons to learn. Oral Maxillofac Surg. 2019;23:187-92.

9. Rood JP, Shehab BA. The radiological prediction of inferior alveolar nerve injury during third molar surgery. Br J Oral Maxillofac Surg. 1990;28:20-25.

10. Patel S, Dawood A, Whaites E, Pitt Ford T. New dimensions in endodontic imaging: part 1 . Conventional and alternative radiographic systems. Int Endod J. 2009;42:447-62.

11. Selvi F, Dodson TB, Nattestad A, Robertson K, Tolstunov L. Factors that are associated with injury to the inferior alveolar nerve in high-risk patients after removal of third molars. Br J Oral Maxillofac Surg. 2013;51:868-73.

12. Renton T, Yilmaz Z. Managing iatrogenic trigeminal nerve injury: a case series and review of the literature. Int J Oral Maxillofac Surg. 2012;41:629-37.

13. Leung YY, McGrath C, Cheung LK. Trigeminal neurosensory deficit and patient reported outcome measures: the effect on quality of life. PLoS One. 2013;8:e773-91.

14. Mahasantipiya PM, Savage NW, Monsour PAJ, Wilson RJ. Narrowing of the inferior dental canal in relation to the lower third molars. Dentomaxillofac Radiol. 2005;34:154-63.

15. Tantanapornkul W, Okochi K, Bhakdinaronk A, Ohbayashi N, Kurabayashi T. Correlation of darkening of impacted mandibular third molar root on digital panoramic images with cone beam computed tomography findings. Dentomaxillofac Radiol. 2009;38:1116.

16. Tolstunov L, Brickeen M, Kamanin V, Susarla SM, Selvi F. Is the angulation of mandibular third molars associated with the thickness of lingual bone? British Journal of Oral and Maxillofacial Surgery. 2016;54:91419.

17. Stacy GC, Orth D. Perforation of the lingual alveolar plate in association with mandibular third molars. Report of a case. Oral Surg Oral Med Oral Pathol. 1964;17:586-91.

18. Al Ali S, Jaber M. Correlation of panoramic high-risk markers with the cone beam CT findings in the preoperative assessment of the mandibular third molars. J Dent Sci. 2020;15:75-83.

19. Huang C, Zhou C, Xu M, Zou D. Risk factors for lingual plate fracture during mandibular third molar extraction. Clin Oral Investig. 2020;24:4133-4142.

20. Wang D, He X, Wang Y, Zhou G, Sun C, Yang L, Bai J, Gao J, Wu Y, Cheng J. Topographic relationship between root apex of mesially and horizontally impacted mandibular third molar and lingual plate: cross-sectional analysis using CBCT. Sci Rep. 2016;6:39268.

21. Aksoy U, Orhan K. Risk Factor in Endodontic Treat- 
ment: Topographic Evaluation of Mandibular Posterior Teeth and Lingual Cortical Plate Using Cone Beam Computed Tomography (CT). Med Sci Monit. 2018;24:7508-16.

22. Huang R-Y, Cochran DL, Cheng W-C, Lin M-H, Fan W-H, Sung C-E, Mau L-P, Huang P-H, Shieh Y-S. Risk of lingual plate perforation for virtual immediate implant placement in the posterior mandible. J Am Dent Assoc. $2015 ; 146: 735-42$.

23. Grau-Manclús V, Gargallo-Albiol J, Almendros-Marqués N, Gay-Escoda C. Mandibular fractures related to the surgical extraction of impacted lower third molars: a report of 11 cases. J Oral Maxillofac Surg. 2011;69:1286-90.

24. Esen E, Aydoğan LB, Akçali MC. Accidental displacement of an impacted mandibular third molar into the lateral pharyngeal space. J Oral Maxillofac Surg. 2000;58:96-97.

25. Ohshima A, Ariji Y, Goto M, Izumi M, Naitoh M, Kurita $\mathrm{K}$, Shimozato K, Ariji E. Anatomical considerations for the spread of odontogenic infection originating from the pericoronitis of impacted mandibular third molar: computed tomographic analyses. Oral Surg Oral Med Oral Pathol Oral Radiol Endod. 2004;98:589-97. 